\title{
Most Common Bulls for Artificial Insemination of Cows and Heifers in a Field of Operation of Veterinary Ambulance Farkasevac
}

\author{
Tusek Tatjana, Alagic Damir, Panic Valentino, Kalember Durica, Nervo Vedran, Stojnovic Miomir \\ Krizevci College of Agriculture, Krizevci, Croatia \\ Email address: \\ ttusek@vguk.hr(T. Tatjana), dalagic@vguk.hr(A.Damir), panicvalentino@gmail.com(P.Valentino),dkalember@vguk.hr(K.Durica), \\ vnervo@vguk.hr(N. Vedran), mstojnovic@vguk.hr(S. Miomir)
}

\section{To cite this article:}

Tusek Tatjana, Alagic Damir, Panic Valentino, Kalember Durica, Nervo Vedran, Stojnovic Miomir. Most Common Bulls for Artificial Insemination of Cows and Heifers in a Field of Operation of Veterinary Ambulance Farkasevac. International Journal of Applied Agricultural Sciences. Vol. 5, No. 4, 2019, pp. 90-93. doi: 10.11648/j.ijaas.20190504.12

Received: July 8, 2019; Accepted: July 26, 2019; Published: August 14, 2019

\begin{abstract}
In a field of operation of Veterinary Ambulance Farkaševac farmers are mainly breeding Simmental cattle, followed by the number of Black Holstein and the Red Holstein used for crossing with Simental breed. The selection of bulls for the artificial insemination of cows and heifers in 2014 and 2015 in the field of operation of Veterinary Ambulance Farkaševac shows the interest of the cattle breeders for the bulls that have the best milking index. Such a unilateral selection of bulls for a well-adapted combined Simmental breed points out the shortcomings of selected bulls with a weak index of meat or legs. With such approaches in the second or third generation, the female calves will become good dairy cows, but will have weak legs and reduced longevity. In the case of male calves for fattening, due to poor meat index, such calves will not grow for 15 to 16 months in quality fattening steers, which will ultimately prolong fattening, increase production costs and reduce the quality of meat on slaughter line.
\end{abstract}

Keywords: Simmental Cattle, Bull, Artificial Insemination

\section{Introduction}

Artificial insemination (AI) has been used in cattle breeding in Croatia for 60 years and has great economic, breeding and hygienic significance [10]. The greatest task of artificial insemination is the rapid spread of the genomes of the best quality breeding bulls with the aim of improving the production properties. Over time, centers have been developed with highvalue breeding bulls kept for ejaculate which is sent to analysis in laboratories and continue to be diluted and preserved. The AI technology has progressed very well and has become the most successful method of cattle breeding. One dose of 0.25 or 0.5 $\mathrm{mL}$ volume, for $\mathrm{AI}$ of cows and heifers, must contain at least 20 to 30 million sperm, of which progressively movable must be at least 15 to 20 million. At least $80 \%$ of progressive spermatozoa, at most $2 \%$ of immature sperm and $18 \%$ of teratological sperm form [1]. Majic Balić (2010) investigated the amounts of ejaculate of bulls younger and older in age during the spring, summer, autumn and winter and found that young bulls in the spring ejaculate an average of $3.73 \pm 1.30 \mathrm{~mL}$, in summer $4.74 \pm$ $1.41 \mathrm{~mL}$, in autumn $4.16 \pm 1.17 \mathrm{~mL}$ and in winter $4.32 \pm 0.75$ $\mathrm{mL}$ of semen, while older bulls in the spring ejaculate on average $5.76 \pm 2.27 \mathrm{~mL}$, in summer $8.97 \pm 3.59 \mathrm{~mL}$, in autumn $6.34 \pm 1.84 \mathrm{~mL}$ and in winter $7.76 \pm 4.04 \mathrm{~mL}$ of semen [7]. The bull ejaculate is taken 2 to 4 times a week. On the day of taking the bull's ejaculate, 2 to 3 ejaculates are taken from the bull, and during the week 4 to 12 ejaculates [7]. It is important to note that the bulls should have one to two days of rest a week. The obtained ejaculate needs to be reviewed and evaluated prior to the application. Particularly important is the evaluation of the ejaculate in breeding bulls used for breeding for the first time [9]. Cows and heifers are mostly inseminated in the stalls at the request of the owner. In this way, the insemination can be performed in optimal time [2].

\section{Material and Methods}

In the field of the Farkaševac Veterinary Ambulance, the 
results of AI of cows and heifers were monitored in 2014 and 2015 and numbered about 500 (average 536 for both years) females of the Simmental breed of cattle or of the same type. The selection of bulls used for breeding is done exclusively with the owner of the cow. The veterinarian selects 10 to 15 bulls not related to cows on the farms monitored by the said veterinarian ambulance. The selection of bulls is from the bulls catalogue of three suppliers of doses for AI of cows, which lists 15 progenitors and 15 genetically tested bulls. Veterinary ambulances usually take bull semen from
Veterinary Station Križevci, Repro Vet, Ltd., Center for artificial insemination of cattle, Ltd., Varaždin and more recently from New Genetics, Ltd. Križevci.

\section{Results and Discussion}

Table 1 shows eleven most commonly used bulls for AI of heifers and cows in 2014, showing bulls whose lower limit was 20 administered doses, and the highest 147 doses used for AI.

Table 1. Semen of bulls used for AI of cows and heifers in 2014.

\begin{tabular}{|c|c|c|c|c|c|c|c|c|}
\hline \multirow{2}{*}{$\begin{array}{l}\text { BULL NAME / } \\
\text { NUMBER }\end{array}$} & \multirow{2}{*}{$\Sigma$} & \multirow{2}{*}{$\mathbf{M}$} & \multicolumn{6}{|c|}{ AI IN THE PERIOD 01.01.2014.-31.12.2014. } \\
\hline & & & 1. AI & 2. AI & 3. AI & 4. AI & 5. AI & 6. AI \\
\hline RAIGRAS / 1 & 147 & 24.5 & 83 & 38 & 17 & 6 & 2 & 1 \\
\hline WIDO / 2 & 91 & 18.2 & 34 & 36 & 15 & 3 & 3 & \\
\hline HUMULUS / 3 & 81 & 13.5 & 30 & 21 & 23 & 3 & 2 & 2 \\
\hline MATTAWA / 4 & 57 & 11.4 & 30 & 12 & 8 & 6 & 1 & / \\
\hline INSCHALLAH / 5 & 53 & 13.3 & 19 & 25 & 6 & 3 & l & l \\
\hline WALGRANDE / 6 & 48 & 9.6 & 15 & 21 & 6 & 2 & 4 & / \\
\hline ESCOBAR / 8 & 28 & 5.6 & 16 & 5 & 3 & 2 & l & 2 \\
\hline POMPEO / 9 & 25 & 4.2 & 8 & 4 & 8 & 2 & 1 & 2 \\
\hline RAIN MAN / 10 & 23 & 3.8 & 5 & 11 & 1 & 3 & 2 & 1 \\
\hline PAUL RED / 11 & 20 & 5.0 & 6 & 9 & 4 & 1 & l & 1 \\
\hline
\end{tabular}

Remark: Bulls No 9 i 10 are of Hereford breed, and No 11 is of Aberdeen Angus breed.

Source: Veterinary Ambulance Farkaševac, 2014.

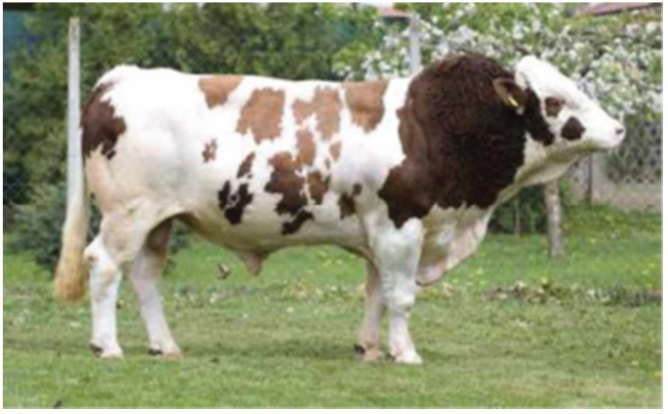

Figure 1. Bull Raigras [6].

It is noticeable that the most used bulls in 2014 were: Raigras (Figure 1), Wido (Figure 2) and Humulus (Figure 3). All three bulls are of Simmental breed with high potential, imported from Germany [6]. The best bull of the three most used bulls in 2014 is Wido (calved: October 29, 2006), a bull with all indexes above 100, which means it is rated above the average. Wido is the type of bull that is desirable to select in any cattle farm because it is extremely good for the production of heifers used in further breeding and milk production, and is also excellent according to the meat index and provides a high quality male calf for fattening. Raigras (calved: 22.05.2006.) and Humulus (calved: 12.10.2008.) are also two quality bulls, which are extremely good for the production of heifers for further breeding, but are slightly worse as far as the production of male calves is concerned, their meat index is somewhat weaker. All three bulls are very long-lasting and will give a female calf that will be able to withstand more than three highly productive lactations. Raigras's daughters have very high production of milk, but weaker in composition. Meat characteristics are average (weak meat yield) and have a weaker foot index. It can be seen from Table 1 that most of the heifers and cows that were inseminated with the semen of these bulls have been pregnant from the first or second insemination. In total, 63\% of cows and heifers were inseminated from Humulus bull semen, $77 \%$ from Wida and $82 \%$ from Raigras bull semen.

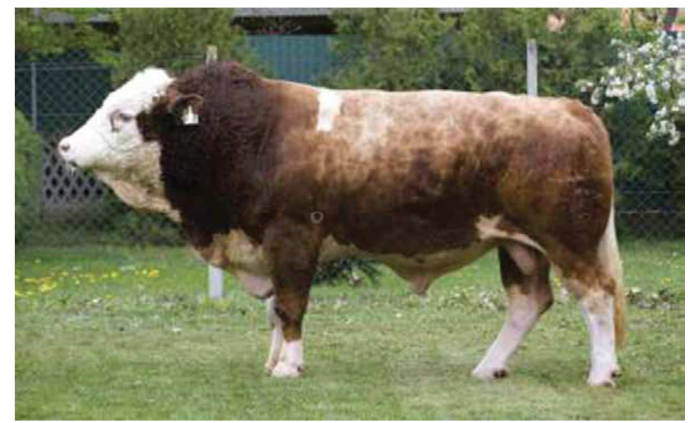

Figure 2. Bull Wido [6].

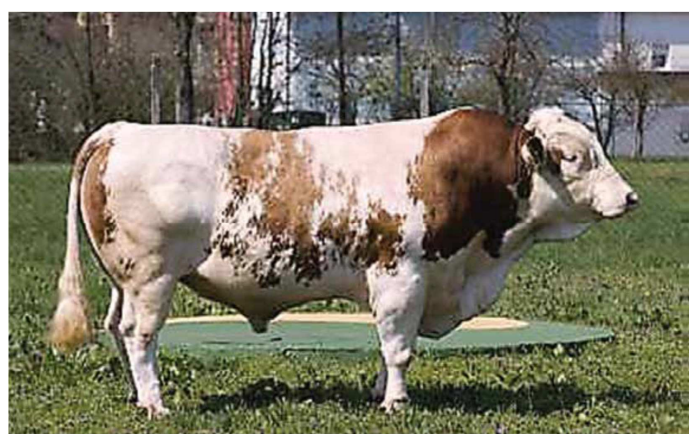

Figure 3. Bull Humulus [6]. 
Table 2 shows the 11 most common bulls for AI of heifers

highest 129 doses for AI. and cows in 2015, with bulls with a lower limit of 23 and the

Table 2. Semen of bulls used for AI of heifers and cows in 2015.

\begin{tabular}{|c|c|c|c|c|c|c|c|c|}
\hline \multirow{2}{*}{ BULL NAME / No. } & \multirow{2}{*}{$\sum$} & \multirow{2}{*}{$\mathbf{M}$} & \multicolumn{6}{|c|}{ AI IN THE PERIOD 01.01.2015. - 31.12.2015. } \\
\hline & & & 1. AI & 2. AI & 3. AI & 4. AI & 5. AI & 6. AI \\
\hline MARTIN / 1 & 129 & 21.5 & 64 & 36 & 14 & 6 & 5 & 4 \\
\hline HUMULUS / 2 & 63 & 10.5 & 18 & 25 & 11 & 7 & 1 & 1 \\
\hline ROSSWAND / 4 & 38 & 6.3 & 13 & 15 & 6 & 1 & 2 & 1 \\
\hline RAUL / 5 & 35 & 7.0 & 22 & 6 & 5 & 1 & l & 1 \\
\hline MAGE / 6 & 29 & 4.8 & 7 & 12 & 2 & 1 & 3 & 4 \\
\hline MANIA / 8 & 28 & 9.3 & 15 & 9 & 4 & l & l & / \\
\hline WALGRANDE / 9 & 25 & 6.3 & 9 & 10 & 4 & 2 & l & / \\
\hline POMPEO / 10 & 24 & 6.0 & 8 & 9 & 5 & 2 & 1 & / \\
\hline WIDO / 11 & 23 & 5.8 & 11 & 5 & 5 & 2 & l & / \\
\hline
\end{tabular}

Remark: Bulls No. 8 i 10 are Hereford breed.

Source: Veterinary Ambulance Farkaševac, 2015.

The most commonly used bulls in 2015 were Martin (calved: August 11, 2012) and Humulus, and Raul (calved: October 18, 2008) was distinguished for a good meat index [3]. Humulus has already been considered, so the description will cover the other two bulls. Martin is a bull (Figure 4), which was not tested in 2015 but was put into free production to see what results would be achieved. A lot of Martin's semen was sold, which is evident from the table, cow and heifers were succesfully inseminated ( $78 \%$ of the two AIs), had good genomic tests on milk, while the meat was quite weak. After the progeny tests were completed, that bull did not satisfy and was withdrawn from the sale. Raul is a bull (Figure 5) who has had excellent tests. After two AIs a total of $80 \%$ of cows and heifers was confirmed pregnant. That bull has a bit weaker milk index, but an extremely good meat index. Raul has been used a lot, but genetic defect has been discovered later, so it is less used today, because farmers today decide on bulls that are not carriers of genetic defects. The success of artificial insemination of heifers and cows observed within the given annual season was highest in spring $(80 \%$ of heifers and cows compared to the total number of inseminations) and in autumn, $70 \%$, in the winter $60 \%$ (mild winter), while only $20 \%$ in the summer [8]. The length of the day and an optimum ambient temperature of $22^{\circ}$ $\mathrm{C}$ had a considerable influence on such data.

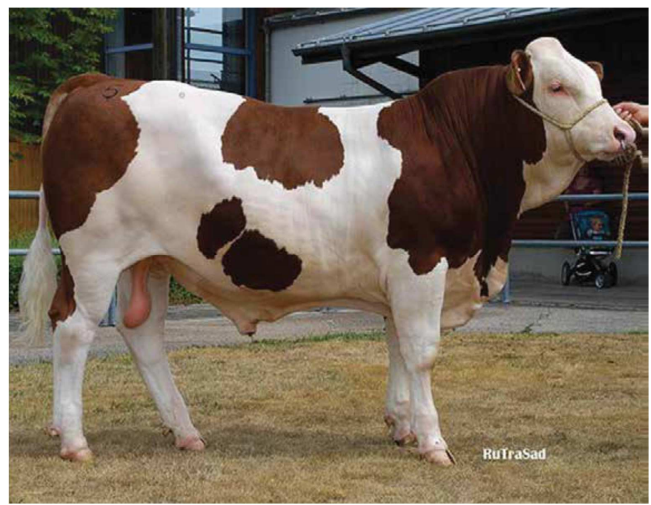

Figure 4. Bull Martin [3].

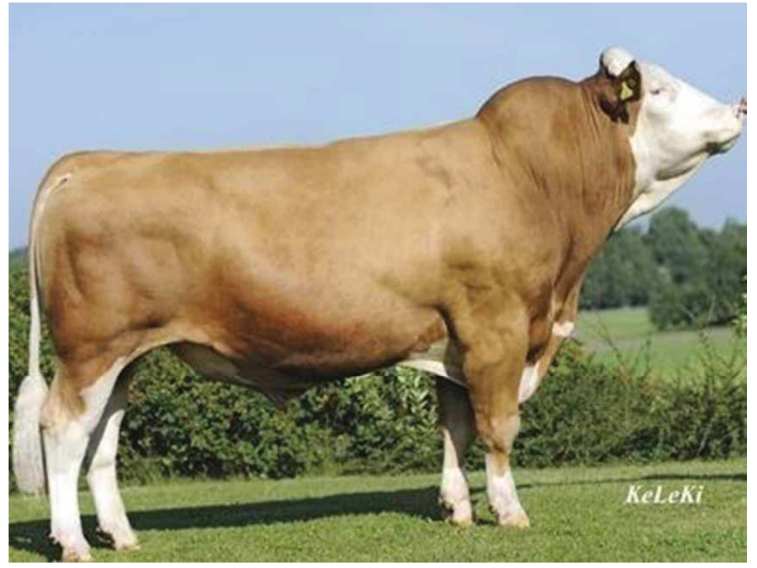

Figure 5. Bull Raul [3].

A fall in the number of cows (total and Simmental breeds) in 2015 compared to 2014 also caused a fall in average consumption of doses of semen per bull between those two years, highlighted in Figure $6[4,5]$. However, in the same chart, we see an increase in the average consumption of doses of semen of bulls (MANIA / 8 and POMPEO / 10) in 2015, which were used as bulls of the Herefod breed for the purpose of repairing meatiness in Simmental cattle.

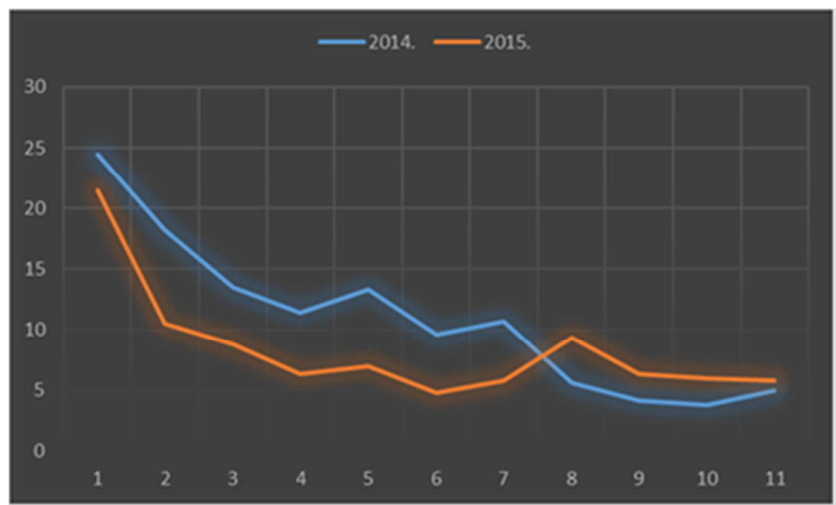

Figure 6. Average values of use of bull semen doses for AI in 2014 and 2015 in 3 to 6 matings. 


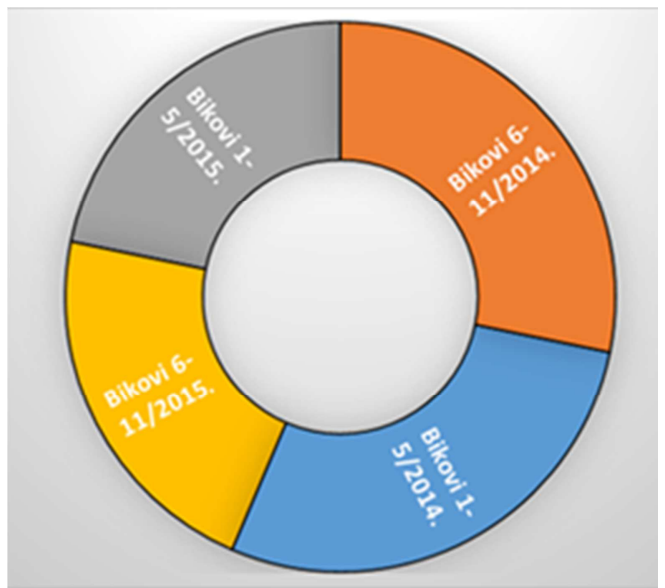

Figure 7. A comparative depiction of the use of bull semen for AI in 2014 and 2015 according to the position on the list (1-5 and 6-11).

The number of doses of semen used is higher for bulls in the list $1-11$ in 2014 compared to 2015 , which is also the result of a larger number of cow holders in 2014 (highlighted in Figure 7). The percent ratio of the use of bull semen doses within a year is $71 \%$ in favor of bulls $1-5 / 2014$ compared to bulls 6-11 / 2014, while this ratio is more even in 2015 and is $66 \%$ for bulls 1-5 / 2015 compared to bulls 6-11 / 2015.

\section{Conclusion}

1. The most common bulls of the Simmental breed for AI of heifers and cows at the choice of cattle breeders in the field of operation of Veterinary Ambulance Farkaševac in 2014 are bulls Raigras, Wido and Humulus, and in 2015 Martin and Humulus.

2. The bulls have a high index for milk and less for meat.

3. The age of selected bulls for AI of heifers and cows ranges between seven and eight years, with the exception of three-year old bull Martin.

4. Young bull Martin has good genomic tests on milk, but after poor results of the progeny testing, it is withdrawn from use.

5. The bull Raul has a weaker milk index, but an extremely good index for meat, he was subsequently diagnosed with the genetic defects, which negatively affected the farmer's interest.
6. All bulls have a high success rate of heifers and cows insemination that are most prominent in the spring.

7. The livestock farmers, according to their interest, prefer the choice of bulls according to the milking index, even though it is a combined type of cattle, which should, through additional education of the farmers, focus on criteria that would equate the breeding of a combined type of Simmental cattle.

\section{References}

[1] Cergolj, M., Samardžija, M. (2006). Veterinary Andrology, Medicinska naklada, Zagreb.

[2] Herak-Perković, V., Grabarević, Ž., Kos, J. (2012). Veterinary Manual 6. Edition. Medicinska naklada, Zagreb.

[3] Croatian Agency for Agriculture (2012 / 2013). Catalogue of live bulls of Simmental breed.

[4] Croatian Agency for Agriculture (2015). Cattle breeding Annual Report 2014. http://hpa.mps.hr/publikacije-godišnjaizvješća/.

[5] Croatian Agency for Agriculture (2016), Cattle breeding Annual Report 2015. http://hpa.mps.hr/publikacije-godišnjaizvješća/.

[6] Catalogue of bulls of Simmental breed (2016 / 2017). Center for artificial insemination of cattle Ltd, Varaždin.

[7] Majić-Balić, I. (2010). Advantages of artificial insemination with deep-frozen bull sperm $(05.09 .2017,15: 25)$. http://www.crsh.hr/content/files/1002-0136-1 govedarstvoprednosti-umjetnog osjemenjivanja.doc.

[8] Plačko Vršnak, D., Mokorić, M., Mikec, K. (2016). Winter analysis 2014.-2015. by type of weather (14. 3. 2018., 10.05 h) http://klima.hr/razno/publikacije/.

[9] Rupić, V. (2015). Reproduction of domestic animals. Zrinski d. d., Čakovec.

[10] Tomašković, A., Makek, Z., Dobranić, T., Samardžija, M. (2007). Breeding of cows and heifers. Faculty of Veterinary Medicine, University of Zagreb.

[11] Data of Veterinary ambulance Farkaševac (2014).

[12] Data of Veterinary ambulance Farkaševac (2015). 